Article

\title{
Phototoxicity Evaluation of Hair Cleansing Conditioners
}

\author{
Kevin M. Towle ${ }^{1, *}$, Ernest S. Fung ${ }^{2}$ and Andrew D. Monnot ${ }^{1}$ \\ 1 Cardno ChemRisk, San Francisco, CA 94104, USA \\ 2 Cardno ChemRisk, Aliso Viejo, CA 92656, USA \\ * Correspondence: kevin.towle@cardno.com
}

Received: 27 July 2019; Accepted: 28 August 2019; Published: 2 September 2019

\begin{abstract}
Photoactivation of cosmetic products and/or their ingredients may be associated with adverse skin reactions. Concerns have been raised regarding potential adverse health effects associated with the use of WEN by Chaz Dean (WCD) hair-cleansing conditioners, including alleged symptoms of redness, burning sensation, and irritation. The objective of this study was to use a validated phototoxicity test to evaluate the phototoxic potential of WCD hair-cleansing conditioners, and to demonstrate this assay's applicability to personal care and cosmetic products. Balb/c 3T3 mouse fibroblast cells were exposed to the test articles for one hour. Following the incubation, one set of treated $3 \mathrm{~T} 3$ cells were irradiated with $5 \mathrm{~J} / \mathrm{cm}^{2}$ Solar Simulated Light (SSL), while a duplicate set of treated $3 \mathrm{~T} 3$ cells were kept in the dark. After UV irradiation, cell viability was determined by neutral red uptake. The difference in cell viability between the SSL exposed and non-exposed 3T3 cells were used to determine the phototoxic potential of the test articles. Under the conditions tested, WCD hair-cleansing conditioners were not phototoxic, while the positive control was significantly phototoxic. Taken together, these results demonstrate that that the use of WCD hair-cleansing conditioners would not be expected to cause phototoxicity in consumers.
\end{abstract}

Keywords: phototoxicity; cosmetics; neutral red uptake

\section{Introduction}

A phototoxic reaction, also known as photoirritation, is an acute light-induced, non-immunological skin response that occurs when a substance is applied to the body and subsequently elicits a toxic skin reaction after exposure to UV light. For a chemical to demonstrate phototoxicity, it must: (1) absorb light within the range of natural sunlight $(290-700 \mathrm{~nm}),(2)$ generate reactive species following absorption of UV-visible light, and (3) be applied to or distribute to light-exposed tissues (e.g., skin) [1]. Symptoms from phototoxic reactions include burning sensations, redness, rashes, lesions, and blistering [2].

There is evidence that photoactivation of cosmetic products and/or their ingredients may be associated with adverse skin reactions. For example, Hans et al. (2008) reported that lipstick and facial cream cosmetic products generated reactive oxygen species, produced hemolysis, and caused lipid peroxidation in human erythrocytes under sunlight exposure [3]. Additionally, ingredients commonly used in personal care and cosmetic products, such as essential oils, fragrance chemicals, and botanicals have been associated with phototoxic effects [4-6]. This is an area of rising interest, given the number of personal care and cosmetic products available on the market, as well as the number of personal care and cosmetic products applied per day [7].

Concerns have been raised regarding potential adverse health effects associated with the use of WEN by Chaz Dean (WCD) hair-cleansing conditioners [8]. WCD hair-cleansing conditioners were designed to eliminate and replace sulfate-containing detergents and other ingredients often present in similar products with a mixture of botanical essential oils. In 2016, the US Food and Drug 
Administration (FDA) announced an investigation of adverse events reported to be associated with the use of WCD hair-cleansing conditioners [9]. Reported adverse events included redness, burning, rashes, and irritation. The FDA noted that it had not determined a possible cause for adverse events, but called on the company to provide data to better understand potential factors of the alleged adverse reactions [9].

No standardized test for phototoxicity is required under current FDA regulations for personal care and cosmetic products; however, if UV exposure is anticipated following product use, evaluation for phototoxic potential may be necessary. Therefore, the objective of this study was to evaluate the phototoxic potential of WCD hair-cleansing conditioners and their ingredients. Specifically, we performed in vitro phototoxicity testing of the three most popular WCD hair-cleansing conditioners. This study demonstrates the use of a reliable predictive test of acute phototoxicity effects to evaluate a personal care or cosmetic product with allegations of adverse skin reactions.

\section{Materials and Methods}

\subsection{Test Articles}

The three top-selling WCD hair cleansing conditioner products (Sweet Almond Mint, Lavender, and Pomegranate) [test articles] and chlorpromazine (positive control) were evaluated in this analysis. Test articles were tested at $0.007 \%, 0.010 \%, 0.015 \%, 0.022 \%, 0.032 \%, 0.046 \%, 0.068 \%$, and $0.10 \%$ in Hanks' Balanced Salt Solution (HBSS). Chlorpromazine was tested at $0.22 \mu \mathrm{g} / \mathrm{mL}, 0.32 \mu \mathrm{g} / \mathrm{mL}, 0.46 \mu \mathrm{g} / \mathrm{mL}$, $0.68 \mu \mathrm{g} / \mathrm{mL}, 1.0 \mu \mathrm{g} / \mathrm{mL}, 1.47 \mu \mathrm{g} / \mathrm{mL}, 2.15 \mu \mathrm{g} / \mathrm{mL}, 3.16 \mu \mathrm{g} / \mathrm{mL}, 6.81 \mu \mathrm{g} / \mathrm{mL}, 10 \mu \mathrm{g} / \mathrm{mL}, 14.7 \mu \mathrm{g} / \mathrm{mL}$, $21.5 \mu \mathrm{g} / \mathrm{mL}, 31.6 \mu \mathrm{g} / \mathrm{mL}, 46.4 \mu \mathrm{g} / \mathrm{mL}, 68.1 \mu \mathrm{g} / \mathrm{mL}$, and $100 \mu \mathrm{g} / \mathrm{mL}$ in HBSS.

\subsection{UV-VIS Spectrum}

The OECD 432 guideline recommend that the ultraviolet-visible light (UV-VIS) absorption spectrum of the test articles be determined prior to in vitro evaluation to determine whether the test article is photoreactive [10]. A UV-VIS spectral scan was performed on a solution containing $1 \mathrm{mg} / \mathrm{mL}$ of the WCD hair-cleansing conditioners in HBSS. A scan encompassing the wavelengths of $200 \mathrm{~nm}$ to $900 \mathrm{~nm}$ was performed using a spectrophotometer (Bio-Tek Instruments) with KCjr software (Bio-Tek Instruments). A peak absorbance (corrected for background) of the solution was determined.

\subsection{Preparation and Treatment}

$\mathrm{Balb} / \mathrm{c} 3 \mathrm{~T} 3$ mouse fibroblast cells were plated and grown to $50-99 \%$ confluence $\left(37 \pm 1{ }^{\circ} \mathrm{C}, 5 \pm 1.0 \%\right.$ $\mathrm{CO}_{2}$ ) in growth medium (Dulbecco's Modified Eagle's Medium containing $0.1 \%$ gentamicin and $10 \%$ fetal bovine serum [DMEM-10-FBS]). Cells were harvested by trypsinization and plated at a density of approximately 10,000 cells/well in the central 60 wells of duplicate 96-well microplates. Media was added to the peripheral wells, which were used as blanks. The two 96-well plates were then dosed with the test articles. Vehicle controls were placed on the left and right columns of the dosing area and consisted of vehicle alone (negative control). Each dosing group consisted of six wells of a microplate treated identically with one concentration of the test article per column. Additionally, duplicate 96-well plates were dosed with 16 serial dilutions of chlorpromazine. Both the test article and positive control duplicate plates were treated for $60 \mathrm{~min}$.

\subsection{Irradiation}

One plate of the treated $3 \mathrm{~T} 3$ cells was subsequently irradiated with a dose of $5 \mathrm{~J} / \mathrm{cm}^{2}$ Solar Simulated Light (SSL) for approximately $50 \mathrm{~min}$ using a SOL 500 Solar Simulator (Honle). To better simulate sunlight, the Solar Simulator was fitted with an H-1 filter to block UVC and more than $99 \%$ UVB radiation. The duplicate plate of treated 3 T3 cells remained in the dark (No SSL). Both analyses were performed at room temperature. 


\subsection{Cell Viability}

Following UV irradiation, 3T3 cells were washed and incubated with culture medium for 18 to $24 \mathrm{~h}$. After incubation, the culture medium was replaced with neutral red medium $(50 \mu \mathrm{g} / \mathrm{mL})$ and the cells were incubated for an additional $3 \mathrm{~h}$. The medium was then discarded, the wells were washed with HBSS, and extraction solution (1\% glacial acetic acid, 50\% ethanol, and $49 \%$ distilled water) was added to each well.

The absorbance of each well was measured at $540 \mathrm{~nm}$ on a MicroQuant plate reader (Bio-Tek Instruments). The uptake of neutral red is proportional to cell viability (as reflected by the optical density at $540 \mathrm{~nm}\left[\mathrm{OD}_{540}\right]$ ]) [10]. The mean optical density values of the blank outer wells (negative control) were used as a reference. Percent viability was calculated as the optical density of the test article divided by the optical density of the negative control. Additionally, the concentration at which cell viability was reduced by $50 \%$ (IC 50 ) was calculated. A photo-irritant factor (PIF; $\mathrm{IC}_{50}$ No SSL $/ \mathrm{IC}_{50}+\mathrm{SSL}_{\mathrm{L}}$ ) of 5.0 or more is indicative of a compound having phototoxic potential, a PIF of greater than 2.0 and less than 5.0 is indicative of a compound having a probable phototoxic potential, and a PIF of less than 2.0 is indicative of a compound having no phototoxic potential. Phototoxic potential criteria are shown in Table 1.

Table 1. Phototoxicity classification criteria per OECD 432 guidelines.

\begin{tabular}{cc}
\hline PIF Range & Classification \\
\hline PIF $<2$ & No phototoxic potential \\
$2<$ PIF $<5$ & Probable phototoxic potential \\
PIF $>5$ & Phototoxic potential \\
\hline \multicolumn{2}{r}{ PIF = photo-irritant factor. }
\end{tabular}

\subsection{Quality Check}

For each phototoxicity assay, neutral red uptake of $3 \mathrm{~T} 3$ cells following treatment with the positive control chlorpromazine was determined in the presence (SSL) and absence (No SSL) of irradiation. Acceptance criteria for the positive control chlorpromazine and negative control are shown in Table 2.

Table 2. Positive and negative control acceptance criteria and results per OECD 432 guidelines.

\begin{tabular}{|c|c|c|c|c|}
\hline Control & Metric & Criteria Range & Test Article & Measured Value \\
\hline Positive control & $\begin{array}{c}\mathrm{IC}_{50 \text { No SSL }} \\
\mathrm{IC}_{50+\mathrm{SSL}} \\
\text { Photo-Irritant Factor } \\
\left(\mathrm{PIF}=\mathrm{IC}_{50 \text { No }} \text { SSL } / \mathrm{IC}_{50+\mathrm{SSL}}\right)\end{array}$ & $\begin{array}{c}7.0-90.0 \mu \mathrm{g} / \mathrm{mL} \\
0.1-2.0 \mu \mathrm{g} / \mathrm{mL} \\
\geq 6\end{array}$ & Chlorpromazine & $\begin{array}{c}22.1 \mu \mathrm{g} / \mathrm{mL} \\
0.4 \mu \mathrm{g} / \mathrm{mL} \\
55.3\end{array}$ \\
\hline Negative control & $\begin{array}{l}\text { Mean } \mathrm{OD}_{540} \text { of all negative controls on a given plate } \\
\text { The difference in the mean of left and right negative } \\
\text { controls compared to the mean of all negative controls } \\
\text { Cell viability of SSL negative control compared to cell } \\
\text { viability of No SSL negative control }\end{array}$ & $\begin{array}{l}\leq 15 \% \\
\geq 80 \%\end{array}$ & $\begin{array}{l}\text { Blank }^{1} \\
\text { Blank }^{2} \\
\text { Blank }^{3} \\
\text { Blank }^{1} \\
\text { Blank }^{2} \\
\text { Blank }^{3} \\
\text { Blank }^{1} \\
\text { Blank }^{2} \\
\text { Blank }^{3}\end{array}$ & $\begin{array}{c}\geq 0.874 \\
\geq 0.832 \\
\geq 0.883 \\
\leq 6 \% \\
\leq 4 \% \\
\leq 7 \% \\
102.7 \% \\
88.9 \% \\
102.5 \%\end{array}$ \\
\hline
\end{tabular}

Blank $^{1}=$ negative controls on WCD Lavender plate; Blank ${ }^{2}=$ negative controls on WCD Pomegranate plate; Blank $^{3}=$ negative controls on WCD Sweet Almond Mint plate; $\mathrm{IC}_{50}=$ concentration at which cell viability was reduced by $50 \% ; \mathrm{OD}_{540}=$ optical density at $540 \mathrm{~nm} ; \mathrm{WCD}=$ WEN by Chaz Dean ${ }^{\circledR} ; \mathrm{SSL}=$ Solar Simulated Light. 


\section{Results}

\subsection{UV-VIS Spectrum}

None of the WCD hair-cleansing conditioners showed significant absorption in the UVA range of $315 \mathrm{~nm}$ to $400 \mathrm{~nm}$ (region of potential reactivity when testing for phototoxicity in the 3T3 assay) or the UVB range of $280 \mathrm{~nm}$ to $315 \mathrm{~nm}$. These results indicate that the WCD hair-cleansing conditioners are not photoreactive.

\subsection{Phototoxicity-Quality Control}

The positive control chlorpromazine reduced cell viability with a PIF of 55.3 and was classified as phototoxic, according to OECD guideline criteria (Table 1). Additionally, the positive and negative control requirements were met for each test of the WCD hair-cleansing conditioners (Table 2).

\subsection{Phototoxicity-WCD Cleansing Conditioners}

The phototoxicity findings for the WCD hair-cleansing conditioners are shown in Table 3. According to OECD guidelines, the WCD hair-cleansing conditioners did not exhibit any phototoxic potential, as $\mathrm{IC}_{50}$ values were greater than $0.1 \%$ (the maximum tested concentration) and the PIF could not be calculated. These results demonstrate that the WCD hair-cleansing conditioners evaluated in this study do not exhibit phototoxicity.

Table 3. WCD Cleansing Conditioner Phototoxicity Test Results.

\begin{tabular}{ccccc}
\hline Test Sample & $\begin{array}{c}\text { Concentration } \\
\text { Range }\end{array}$ & $\begin{array}{c}\text { IC }_{50} \\
\text { No SSL }\end{array}$ & $\begin{array}{c}\text { IC }_{50} \\
\text { +SSL }\end{array}$ & PIF \\
\hline WCD Sweet Almond Mint cleansing conditioner & $0.007-0.1 \%$ & $>0.1 \%$ & $>0.1 \%$ & $\mathrm{n} / \mathrm{a}$ * \\
WCD Lavender cleansing conditioner & $0.007-0.1 \%$ & $>0.1 \%$ & $>0.1 \%$ & $\mathrm{n} / \mathrm{a}$ * \\
WCD Pomegranate cleansing conditioner & $0.007-0.1 \%$ & $>0.1 \%$ & $>0.1 \%$ & $\mathrm{n} / \mathrm{a} *$ \\
\hline
\end{tabular}

PIF = photo-irritant factor; $\mathrm{WCD}=\mathrm{WEN}$ by Chaz Dean ${ }^{\circledR} ; \mathrm{SSL}=$ Solar Simulated Light; $\mathrm{IC}_{50}=$ half maximal effective concentration. * PIF could not be calculated since $\mathrm{IC}_{50}$ values for both No SSL and +SSL results were $>0.1 \%$.

Results are also presented as percent of vehicle treatment (negative control) for the WCD hair-cleansing conditioners (Figures 1-3) and positive control chlorpromazine (Figure 4). The mean $\mathrm{OD}_{540}$ of the non-irradiated controls (No SSL) and irradiated controls (SSL) for each test was set to 100\% control (Figures 1-4).

틀 No SSL ESL

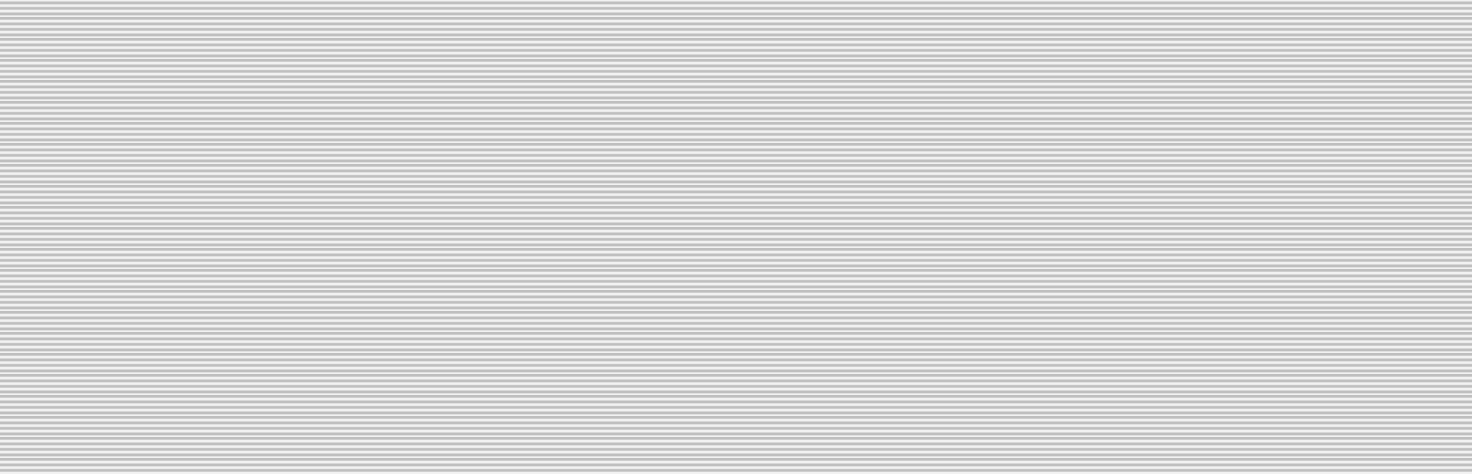

Figure 1. Lavender results. Cell viability by concentration of Lavender WCD cleansing conditioner, stratified by with and without solar simulated light (SSL). 
를 No SSL 틀 SSL

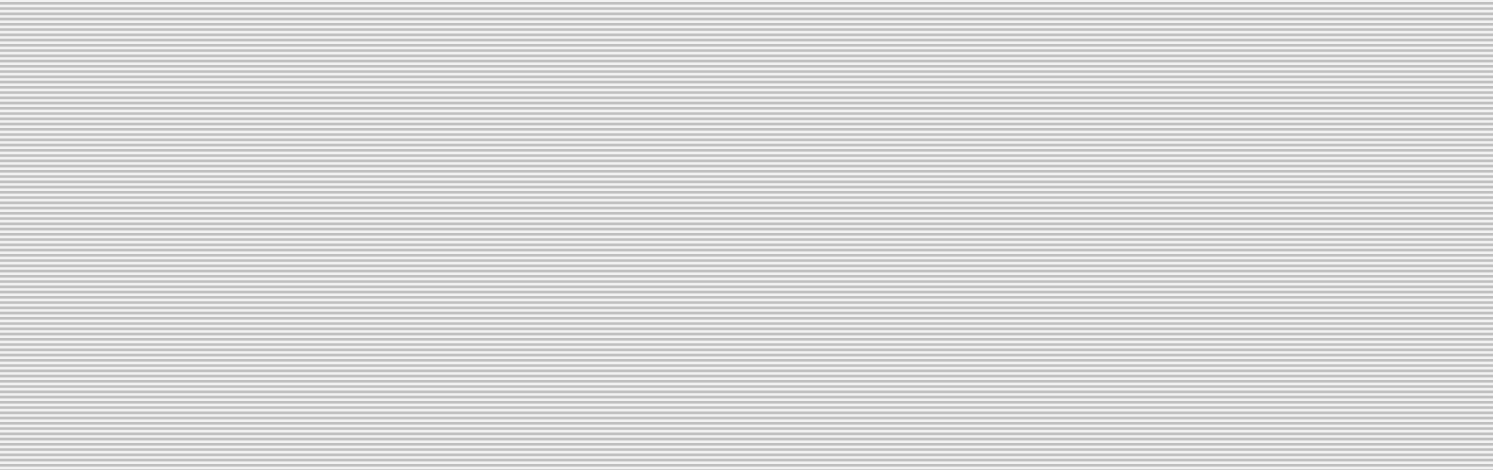

Figure 2. Pomegranate results. Cell viability by concentration of Pomegranate WCD cleansing conditioner, stratified by with and without solar simulated light (SSL).

틀 No SSL $\equiv$ SSL

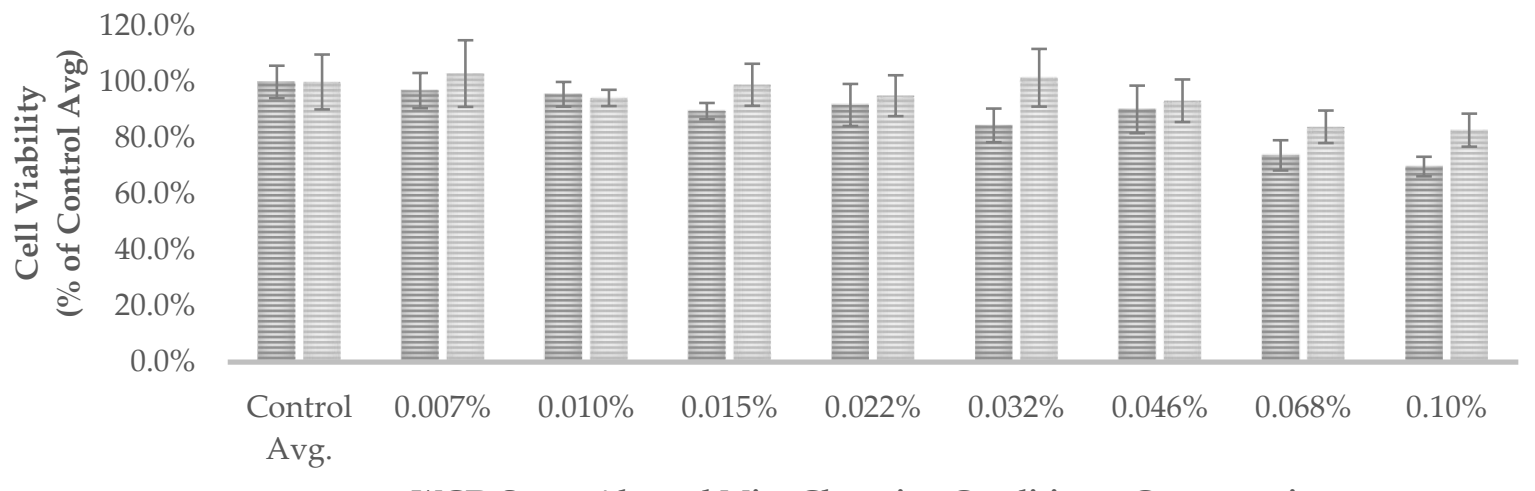

WCD Sweet Almond Mint Cleansing Conditioner Concentration

Figure 3. Sweet Almond Mint results. Cell viability by concentration of Sweet Almond Mint WCD cleansing conditioner, stratified by with and without solar simulated light (SSL).

를 No SSL 를 SSL

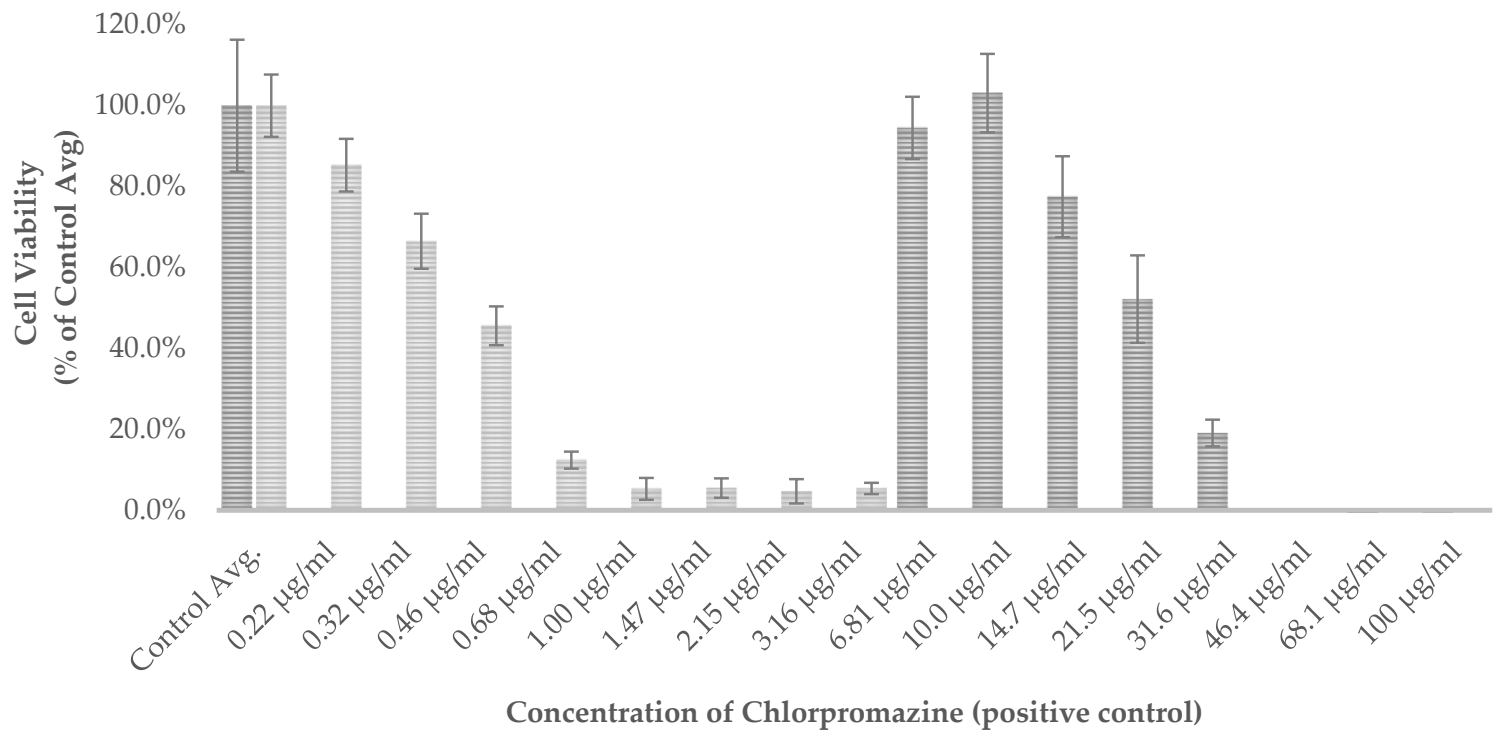

Figure 4. Positive control results. Cell viability by concentration of chlorpromazine (positive control), stratified by with and without solar simulated light (SSL). 


\section{Discussion}

This analysis performed an in vitro phototoxicity assay on three popular WCD hair-cleansing conditioners that have allegations of adverse skin reactions. Based on findings from this study, the evaluated WCD hair-cleansing conditioners were not considered to have phototoxic potential at the concentrations tested in the 3T3 Neutral Red Uptake Phototoxicity Test.

The FDA's Center for Food Safety and Applied Nutrition's Adverse Event Reporting System (CFSAN) contains information on adverse events and product complaint reports submitted to the FDA for foods, dietary supplements, and cosmetics [11]. This data was made publicly available in 2016 in an effort to increase transparency of the safety surveillance program. Specific reported symptoms included burning sensation, irritation, rash, and ulcers [11].

Given that no standardized test for phototoxicity is required under current FDA regulations for personal care and cosmetic products, this analysis demonstrates the use of a reliable predictive test of acute phototoxicity effects to evaluate a personal care product with allegations of adverse skin reactions. Both the European Centre for the Validation of Alternative Methods and the European Cosmetic, Toiletry, and Perfumery Association concluded that the 3T3 Neutral Red Uptake Phototoxicity Test is a scientifically validated in vitro test that can be used for regulatory purposes for assessing the phototoxicity potential of chemicals [12]. It has also been reported that the test is characterized by high sensitivity, specificity, and reproducibility, and has achieved a correlation between in vivo and in vitro results of between $95 \%$ and $100 \%$ [6]. This is particularly relevant given the global push to utilize alternative tests to assess product safety that removes the need for animal testing, including new legislation in California to prohibit the sale of cosmetic products and ingredients tested on animals [13]. This methodology is consistent with other analyses that have used the 3T3 Neutral Red Uptake Phototoxicity Test to examine the phototoxicity of personal care and cosmetic products [14-16].

Although the OECD 432 is a validated in vitro guideline study, it is not without limitations. The guideline is limited by the solubility of the test article. If the test article is overly viscous and cannot be readily dissolved, it may be difficult to apply to the cells and may cause viscosity-related cell death. Thus, the observed cell death may not accurately reflect the test article's phototoxic potential. Additionally, the color of the test article may interfere with the results of the study. If the test article overlaps the $540 \mathrm{~nm}$ wavelength for the neural red uptake analysis, the residual test article in the media may interfere with the analysis and not accurately reflect cell viability after treatment.

Our findings provide evidence that the use of WCD hair-cleansing conditioners would not be expected to cause phototoxicity in consumers using these products under their intended conditions of use. These results agree with previous analyses that suggest that use of WCD hair-cleansing conditioners would not be expected to cause skin irritation or induce skin sensitization among consumers [17,18]. Additional testing may be needed to assess the safety of this product line.

Author Contributions: All authors participated in the design, implementation, drafting, and review of the manuscript. Conceptualization, K.M.T., E.S.F. and A.D.M.; Formal analysis, K.M.T., E.S.F. and A.D.M.; Methodology, K.M.T., E.S.F. and A.D.M.; Writing-original draft, K.M.T., E.S.F. and A.D.M.

Funding: This research was funded by WEN Chaz Dean (WCD).

Conflicts of Interest: Authors KMT, ESF, and ADM are employed by Cardno ChemRisk, a consulting firm that provides scientific advice to the government, corporations, law firms, and various scientific/professional organizations. Cardno ChemRisk has been engaged by WEN Chaz Dean (WCD), which produces personal care products, including the products examined in this study. Funding for the research and preparation of this article was provided by WCD. This paper was prepared and written exclusively by the authors without review or comment by any outside entity. 


\section{References}

1. FDA. S10 Photosafety Evaluation of Pharmaceuticals: Guidance for Industry; FDA-Center for Drug Evaluation Research/Center for Biologics Evaluation and Research: Silver Spring, MD, USA, January 2015. Available online: https://www.fda.gov/regulatory-information/search-fda-guidance-documents/s10-photosafetyevaluation-pharmaceuticals (accessed on 2 September 2019).

2. Iwona, J.; Kozlowicz, K.; Sokolowska, A.; Kwiatek, J. Phototoxic and photoallergic reactions after cosmetics. Arch. Physiother. Glob. Res. 2014, 18, 21-22.

3. Hans, R.K.; Agrawal, N.; Verma, K.; Misra, R.B.; Ray, R.S.; Farooq, M. Assessment of the phototoxic potential of cosmetic products. Food Chem. Tox. 2008, 46, 1653-1658. [CrossRef]

4. Placzek, M.; Fromel, W.; Eberlein, B.; Gilbertz, K.P.; Przybilla, B. Evaluation of phototoxic properties of fragrances. Acta Derm. Vener. 2007, 87, 312-316. [CrossRef]

5. Antignac, E.; Nohynek, G.J.; Re, T.; Clozeau, J.; Toutain, H. Safety of botanical ingredients in personal care products/cosmetics. Food Chem. Toxicol. 2011, 49, 324-341. [CrossRef]

6. Dijoux, N.; Guingand, Y.; Bourgeois, C.; Durand, S.; Fromageot, C.; Combe, C.; Ferret, P.J. Assessment of the phototoxic hazard of some essential oils using modified 3 T3 neutral red uptake assay. Tox. Vitr. 2006, 20, 480-489.

7. Nigam, P.K. Adverse reactions to cosmetics and methods of testing. Indian J. Derm. Vener. Leprol. 2009, 75, 10. [CrossRef]

8. Kwa, M.; Welty, L.J.; Xu, S. Adverse events reported to the US Food and Drug Administration for cosmetics and personal care products. JAMA Intern. Med. 2017, 177, 1202. [CrossRef] [PubMed]

9. FDA. Statement on FDA Investigation of WEN by Chaz Dean Cleansing Conditioners. 2017. Available online: https://www.fda.gov/Cosmetics/ProductsIngredients/Products/ucm511626.htm (accessed on 29 August 2019).

10. OECD. OECD Guideline for Testing of Chemicals: In Vitro 3T3 NRU Phototoxicity Test. No 432. Adopted 13 April 2004, Organisation for Economic Co-operation and Development (OECD). Available online: https://www.oecd-ilibrary.org/environment/test-no-432-in-vitro-3t3-nru-phototoxicitytest_9789264071162-en (accessed on 2 September 2019).

11. FDA. CFSAN Adverse Event Reporting System (CAERS). Available online: https://www.fda.gov/food/ compliance-enforcement-food/cfsan-adverse-event-reporting-system-caers (accessed on 29 August 2019).

12. Spielmann, H.; Balls, M.; Dupuis, J.; Pape, W.J.; Pechovitch, G.; de Silva, O.; Holzhütter, H.-G.; Clothier, R.; Desolle, P.; Gerberick, F.; et al. The international EU/COLIPA in vitro phototoxicity validation study: Results of phase II (blind trial). Part 1: The 3T3 NRU phototoxicity test. Tox. Vitr. 1998, 12, 305-327. [CrossRef]

13. Sanzo, K.; James, C.; Sanchez, A. Insight: New Californa Law Will Ban Sale of Cosmetics Tested on Animals. 1 November 2018. Available online: https://news.bloomberglaw.com/product-liability-and-toxics-law/insightnew-california-law-will-ban-sale-of-cosmetics-tested-on-animals (accessed on 29 August 2019).

14. Yanga, Y.; Xiong, X.; Yang, X.; Huan, J.; Tan, X.; Xie, X.; Zheng, H.; Li, Q.; He, X. Establishment and use of 3t3 NRU assay for assessment of phototoxic hazard of cosmetic products. AATEX 2007, 14, 515-518.

15. Zanatta, C.F.; Ugartondo, V.; Mitjans, M.; Rocha-Filho, P.A.; Vinardell, M.P. Low cytotoxicity of creams and lotions formulated with Buriti oil (Mauritia flexuosa) assessed by the neutral red release test. Food Chem. Tox. 2008, 46, 2776-2781. [CrossRef] [PubMed]

16. Tomankova, K.; Kejlova, K.; Binder, S.; Daskova, A.; Zapletalova, J.; Bendova, H.; Kolarova, H.; Jirova, D. In vitro cytotoxicity and phototoxicity study of cosmetics colorants. Tox. Vitr. 2011, 25, 1242-1250. [CrossRef] [PubMed] 
17. Fung, E.S.; Novick, R.M.; Drechsel, D.A.; Towle, K.M.; Paustenbach, D.J.; Monnot, A.D. Tier-based skin irritation testing of hair cleansing conditioners and their constituents. Cutan. Ocul. Tox. 2019, 38, 44-47. [CrossRef] [PubMed]

18. Fung, E.S.; Novick, D.; Drechsel, D.; Towle, K.; Paustenbach, D.; Monnot, A. Tier-based safety testing of common personal care products and their constituents. Abstr. 2917 Toxicol. 2018, 162, 463.

(C) 2019 by the authors. Licensee MDPI, Basel, Switzerland. This article is an open access article distributed under the terms and conditions of the Creative Commons Attribution (CC BY) license (http://creativecommons.org/licenses/by/4.0/). 